\title{
0 que quer a lingüística e 0 que se quer da lingüística - a delicada questão da assessoria lingüística no movimento indígena
}

\author{
Gilvan Müller de Oliveira*
}

\begin{abstract}
RESUMO: O texto aponta para o fato de que o compromisso do lingüista envolvido com sociedades indígenas não pode ser, ao contrário da crença generalizada, o de elaboração de descrições das línguas indígenas, já que as descrições não são essenciais ao processo de criação de tradições escritas para línguas antes ágrafas.
\end{abstract}

Palavras-chave: Sociedades indígenas, assessoria lingüística, sistema de escrita, planejamento linguístico, escola indígena

Como lingüista e assessor de projetos de educação escolar indígena, mais especificamente em cursos de formação de professores indígenas, desde 1991, acredito que minha contribuição maior neste texto está em discutir o papel dos assessores dos projetos de educação escolar indígena em geral e o papel dos lingüistas em particular, o que, creio, acabará tendo uma série de repercussões interessantes para o tema "Ação pedagógica e alteridade".

Essa centralidade da figura do lingüista foi conseqüência, entre outras coisas, da intimidação causada nos pedagogos pelo seu instrumental de trabalho - bastante impressionante para o leigo - e que freqüentemente fez e ainda faz crer que as respostas para as questões suscitadas na educação bilíngüe em geral e em especial no caso dos povos indíge-

\footnotetext{
* Lingüista. Professor na Universidade Federal de Santa Catarina (UFSC), Florianópolis.

E-mail: gilvan@cce.ufsc.br
} 
nas, são deduzíveis "científica"e univocamente do aparato de análise do lingüista, empurrando as decisões, por tanto, para um âmbito além (ou aquém) do político. Posição conquistada pelos missionários-lingüistas do Summer Institute of Linguistics (SIL) ${ }^{1}$, gerou uma forma de trabalho dos lingüistas em relação à educação indígena que resistiu (e que continua resistindo) durante muito tempo à crítica. Práticas pedagógicas do Summer permaneceram (ainda que de forma diluída) no fazer de muitos lingüistas brasileiros bastante tempo depois de as posições político-ideológicas do SIL terem sido combatidas pela crítica.

Ambas as instâncias se confundem: povo indígena e assessoria têm seus destinos fortemente associados, quase como se se tratasse de uma coisa só. Há o perigo de que o projeto do assessor não deixe espaço para o projeto do povo indígena. O efeito disso é que, em muitos casos, a saída da assessoria, seu desligamento do trabaIho por uma razão ou por outra, leva à descontinuidade dos projetos. Quando o projeto não é o do assessor, mas o do povo indígena, os fatos mostram o exemplo contrário: o assessor deixa o trabalho e ele continua, desenvolve-se em direções inesperadas, adquirindo uma nova qualidade.

Em seu texto "A conquista da escola: Educação escolar indígena e movimento de professores indígenas no Brasil” (1994), o antropólogo Márcio Ferreira da Silva chama nossa atenção para a impressão de uma liderança indígena sobre as assessorias, o professor Baniwa Gersen dos Santos Luciano. Ele comentava em debate ocorrido em 1991: "Quem tem poder no Congresso Nacional, os parlamentares ou seus assessores? Será que os assessores dos não-índios têm tanto poder quanto os nossos?"

Tomando como exemplo o caso dos lingüistas, que conheço meIhor, gostaria de argumentar que muitas das justificativas dadas por esses profissionais para o trabalho com as línguas indígenas têm compromisso muito maior com a tradição da própria disciplina do que com as necessidades dos professores indígenas e dos projetos que os contratam. Com isso quero dizer que a forma de atuação do lingüista em projetos de educação indígena - a forma como ele vê suas responsabilidades e tarefas - pode ser mais prejudicial do que benéfica para o projeto político-pedagógico dos povos indígenas.

É claro que não se trata aqui de analisar o trabalho individual deste ou daquele lingüista. Isso não teria nenhuma função. Trata-se de verificar de que maneira um modus operandi bastante generalizado, decor- 
rente de um conjunto de crenças que circulam nos meios lingüísticos brasileiros, tem produzido um certo tipo de atuação como assessoria.

Nesse sentido, gostaria de comentar também que esse conjunto de crenças antes aproxima os lingüistas brasileiros do que os diferencia entre si. Ou seja: trata-se de uma compreensão muito comum, muito generalizada, decorrente, entre outras razões, do fato de que, na origem da formação do campo de "lingüística indígena" no Brasil está o Summer Institute of Linguistics, o SIL, hoje abreviatura de "Sociedade Internacional de Lingüística".

Muitos lingüistas acreditam que seu papel é descrever as línguas indígenas e que essa descrição, materializada (ou não) nos instrumentos lingüísticos dela decorrentes (alfabetos, ortografias, gramáticas, dicionários e outros), é fundamental para as escolas indígenas. Sua atuação nos projetos educacionais está intimamente ligada a essa crença: muitos crêem que seu papel está em fazer um alfabeto para a língua, em desenvolver uma ortografia unitária para ela, em instrumentalizar uma gramática da língua e em treinar os professores indígenas (até recentemente chamados "monitores indígenas", em posição subalterna aos professores brancos) em discussões sobre a gramática da sua língua, em geral em uma perspectiva comparada. Isto é, crêem ser seu papel promover o conhecimento metalingüístico dos professores indígenas, conhecimento este que é definidor do seu próprio domínio e campo de formação. Essa prática é relativamente comum, sendo executada de sul a norte do país. Crêem, finalmente, que esses passos têm que ser dados previamente à constituição da língua indígena como língua escrita.

Em "As línguas não têm donos", Wetzels (1997, p. 5) argumenta que o lingüista "tem um débito em relação à sociedade da qual ele é membro" e que a tarefa fundamental do lingüista brasileiro seria a de descrever as línguas indígenas, muito mais do que se envolver na produção da chamada "lingüística teórica". Acredita, como muitos outros lingüistas estudiosos dessa temática, que a descrição é essencial para que os indígenas possam adquirir a escrita em sua própria língua:

Furthermore, especially for the tribes that are in regular contact with the Brazilian civilisation, the availability of a standard transcription of their language will permit them to acquire literacy in their own language, fortifying group identity and self-esteem, and also allow a solid bilingual education. (Wetzels 1997, p. 15) 
(Além disso, especialmente para as tribos que estão em contato regular com a civilização brasileira, a disponibilidade de uma descrição padronizada da sua língua Ihes permitirá adquirir a escrita na sua própria língua, fortificando a identidade grupal e a auto-estima, e também propiciará uma sólida educação bilíngüe.)

Evidentemente, a "literalização" de uma língua antes ágrafa - isto é, a sua transformação em língua escrita - tem sido vista por amplos setores que atuam na área de educação escolar indígena como intimamente associada ao empreendimento escolar. A possibilidade de uma escola sem a língua escrita é fato difícil de conceber para a maioria das pessoas que trabalham com educação - indígena ou não -, embora seja um empreendimento logicamente possível. Faz parte do pensamento majoritário a indissociabilidade entre escola e escrita, como é a prática no mundo dito ocidental.

Nesse sentido, praticamente todos os setores envolvidos com educação escolar indígena no Brasil hoje têm uma visão positiva da escrita das línguas indígenas: não conheço ninguém atuando nas assessorias aos projetos que tenha uma crítica articulada e uma proposta alternativa à concepção de que é preciso instrumentalizar as línguas indígenas como línguas escritas para o seu funcionamento escolar. Vamos aceitar, então, provisoriamente, esse fato como positivo, para não iniciar outra linha de argumentação antes de terminar a primeira. Deixemos para discutir essa questão com mais detalhe em outra oportunidade.

As descrições lingüísticas não são, entretanto, ao contrário do que se quer fazer crer, conditio sine qua non para a constituição das línguas indígenas como línguas escritas, como também não o foram, num certo sentido, para as línguas européias. A constituição dessas línguas minoritárias como línguas escritas - sempre considerando que isso tenha sido uma deliberação, a expressão da vontade de uma dada comunidade e não uma imposição ou um "hábito" - tem de ser feita paulatinamente pelos próprios professores e alunos indígenas. A padronização da língua escrita, sua normatização, será o resultado e não a causa do processo de criação da tradição escrita.

Quero argumentar que a descrição de línguas, nos moldes tradicionais, não é a principal responsabilidade dos lingüistas nos projetos de educação escolar indígena, e isso por duas razões. 
Em primeiro lugar, porque o desenvolvimento de uma tradição escrita não depende de haver uma formalização prévia da gramática, nem mesmo de haver uma ortografia unificada, e muito menos de haver uma norma lingüística escrita fortemente fixada.

Em segundo lugar, porque essa concepção que ora critico estabelece um papel excessivamente forte do lingüista no processo e um papel excessivamente fraco do professor indígena, quando, na verdade, precisamos inverter as posições. Os professores indígenas não podem ocupar o papel de "informantes", nem de pessoas que simplesmente vão homologar ou não um trabalho - o do lingüista - que, para eles, se configura como uma espécie de "caixa-preta": um conhecimento que, além de vir de fora e não ser dominado pelo grupo, ainda conduz os desenvolvimentos da prática pedagógica com as línguas por meio de uma racionalidade técnica que dá a impressão de ser a única correta ou possível e que funciona como fator limitante das experiências humanas historicamente possíveis.

Voltemos ao ponto primeiro para explicitar melhor o que quero dizer quando afirmo que as descrições lingüísticas não são condição necessária para o desenvolvimento de tradições escritas. A nossa própria experiência histórica, para citar um exemplo importante, contradiz essa crença, porque primeiro desenvolvemos uma tradição escrita na língua portuguesa, para só depois aparecerem as tentativas de formalização da língua ou de uma variedade da língua escrita - a norma - em forma de gramática. A padronização ortográfica é ainda muito posterior, e foi um dos últimos aspectos da história da escrita das línguas européias. Naturalmente, com esse argumento, não quero dizer que as línguas indígenas seguirão esse caminho percorrido ao longo de vários séculos pela língua portuguesa, ou que a língua portuguesa seja um padrão a seguir: cada língua está inserida num contexto histórico determinado e, além disso, pela própria consciência que temos hoje sobre as línguas e seu papel identitário, o poder de intervenção, seja externo, seja dos próprios usuários do idioma, sobre sua forma e conteúdos, tende a ser muito maior e a acelerar certos passos. No entanto, ver o que aconteceu com a língua portuguesa nos ajuda a relativizar a ordem das necessidades para o surgimento de línguas escritas.

Os primeiros documentos escritos em língua portuguesa de que temos notícia datam do final do século XII e do início do século XIII. Nos séculos XIII, XIV e XV Portugal conheceu um rico e rápido desenvolvimento na área da escrita, tanto por meio de uma florescente atividade literá- 
ria que chegou até nós pelos cancioneiros medievais, quanto por uma intensa atividade escrita para fins funcionais os mais variados, o que chamaríamos hoje de escritos burocráticos.

A primeira gramática da língua portuguesa, entretanto, data de 1536, quase na metade do século XVI portanto, e foi escrita por Fernão de Oliveira. A segunda é a gramática de João de Barros, de 1540. A língua portuguesa, então, funcionou como língua escrita por mais de 300 anos sem que instrumentos lingüísticos de formalização e normatização intercedessem no processo. A gramática de Fernão de Oliveira, aliás, nem tinha o objetivo de possibilitar ou conduzir ao desenvolvimento da escrita - isso nem passaria pela sua cabeça, já que a escrita existia e florescia independente dela -, e sim o objetivo de mostrar o quão a língua portuguesa era semelhante ao latim, numa época em que essa semelhança significava prestígio e na qual esse prestígio era importante para assegurar aos Estados sua independência e poder político. Cito, da obra Linguagem, escrita e poder (1987), de Maurizzio Gnerre o seguinte trecho:

\begin{abstract}
Somente com o começo da expansão colonial ibérica, na segunda metade do século XV, e com a estruturação definitiva dos poderes centrais dos estados europeus, os moldes da gramática greco-latina (segundo a tradição de sistematização de Dionísio da Trácia) foram utilizados para valorizar as variedades lingüísticas escritas, já associadas com os poderes centrais e/ou com as regiões economicamente mais fortes. (Gnerre 1987, p. 9)
\end{abstract}

A normatização ortográfica da língua escrita, isto é, o estabelecimento de que cada palavra só pode ser escrita de uma forma, de que há uma relação unívoca entre uma palavra e a forma de escrevê-la, é um fato do século XIX, não só para o português, mas também para a maioria das línguas européias. Faz pouco mais de 150 anos que temos uma ortografia no sentido estrito do termo. Ou seja, o português funcionou como língua escrita durante 600 anos antes de uma fixação ortográfica mais rígida.

Tenho trabalhado em um projeto de edição dos documentos manuscritos originais do período colonial de Santa Catarina - 1703 a 1830 -, para citar um exemplo, e vejo cotidianamente que nesses documentos - como a correspondência do governador da capitania, processos judiciais e ofícios de diversos órgãos, entre outros - a ortografia das palavras era flutuante: ora escrevia-se tal palavra de uma forma, ora escre- 
via-se de outra, freqüentemente no mesmo texto, sem que isso prejudicasse em nada a compreensão ou a funcionalidade dos escritos.

Convém lembrar aqui a diferença entre alfabeto e ortografia: alfabeto é o conjunto de letras que pode ser usado para escrever uma língua dada; um conjunto de símbolos que apanha o principal das distinções fonético-fonológicas (mais fonológicas do que fonéticas, embora não exclusivamente) daquela língua. Ortografia, por outro lado, como o nome já diz, "escrita correta", refere-se a outro fato, relativamente moderno na história das línguas escritas, que é a convencionalização da forma de escrita de cada palavra, além da convencionalização de outros procedimentos gráfico-textuais.

Sem um livro de gramática e sem uma ortografia fixa, é bom lembrar, a língua portuguesa chegou ao período que os historiadores do idioma chamam de "Período Clássico". Portugal, com o uso da sua língua escrita, construiu seu Império em quatro continentes. Não lhe fez falta a padronização ortográfica para a utilização eficiente de sua escrita. Gostaria de lembrar, com Bakhtin, que

Os criadores - iniciadores de novas correntes ideológicas - (..) [não] sentem necessidade de formalizar sistematicamente. A sistematização aparece quando nos sentimos sob a dominação de um pensamento autoritário aceito como tal. É preciso que a época de criatividade acabe: só aí é que então começa a sistematizaçãoformalização; é o trabalho dos herdeiros e dos epígonos dominados pela palavra alheia que parou de ressoar. A orientação da corrente em evolução nunca pode ser formalizada e sistematizada. Esta é a razão pela qual o pensamento gramatical formalista e sistematizante desenvolveu-se com toda plenitude e vigor no campo das línguas mortas e, ainda, somente nos casos em que essas línguas perderam, até certo ponto, sua influência e seu caráter autoritário sagrado. A reflexão lingüística de caráter formal-sistemático foi inevitavelmente coagida a adotar em relação às línguas vivas uma posição conservadora acadêmica, isto é, tratar a língua viva como se fosse algo acabado, o que implica uma atitude hostil em relação a todas as inovações lingüísticas. [E diríamos, também às variedades (nota do autor).] (Bakhtin/Voloshinov 1978, p. 89 apud Gnerre 1987, pp. 11-12)

Tenho visto professores indígenas discutirem durante anos a necessidade de reformas na escrita, a conveniência de alterações no alfabeto, buscando a fixação de uma ortografia unificada, auxiliados por as- 
sessorias lingüísticas. Essa discussão tem, para alguns grupos mais do que para outros, tomado muito tempo dos professores indígenas.

Enquanto isso, enquanto nutrimos eternamente esse tema, deixamos - professores indígenas e assessorias - de encaminhar o principal: o desenvolvimento de tradições escritas nas línguas indígenas. A questão é muito simples: se a escrita e seu ensino na escola devem fazer algum sentido para as comunidades indígenas, é preciso que a escrita exista fora da escola, isto é, é preciso que existam materiais escritos circulando nas línguas indígenas, é preciso que esses materiais escritos sejam expressão de interesses de leitura, de aprendizado, de lazer, de informação das populações indígenas.

Do contrário, o ensino da escrita será como o é para nossa população pobre, urbana ou rural: de pouca valia, porque não é um instrumento para um projeto próprio, uma vez que seus usuários estarão de antemão alijados da posição de produtores de textos escritos com potencialidade de circulação, fato essencial para a visualização do objetivo de ler e escrever.

Enquanto discutimos a reforma do alfabeto, a fixação da ortografia, deixamos de prestar atenção ao desenvolvimento, agora, dessas tradições escritas. Há hoje, depois de tantos anos de educação escolar indígena, pouquíssimo material significativo escrito nas línguas indígenas. Há os Novos Testamentos dos missionários e há as cartilhas, todas absolutamente parecidas entre si, para a alfabetização. Pouquíssimos povos indígenas têm projetos editoriais nas suas línguas, poucos têm um corpo de pessoas que escrevem e publicam com regularidade. O Acre, para citar um exemplo, tem uma experiência interessante de autoria de produção permanente de materiais escritos pelos professores indígenas.

O lingüista tem a obrigação de desfazer esse equívoco: ortografias e normas escritas unificadas são o resultado do processo de criação de uma tradição escrita. Não podem ser feitas sem o desenvolvimento, no mais das vezes demorado, de uma tradição escrita, sem o fluxo da historicidade própria que esse desenvolvimento traz consigo, a não ser como um esforço irremediavelmente tecnocrático. E todo agir tecnocrático demanda tecnocratas.

Dado esse raciocínio, modifica-se a ação do lingüista: sua atuação passa a ser muito mais a de elucidação conceitual da reflexão lingüística conduzida pelos próprios falantes, que se constituem em pesquisadores 
de suas próprias línguas. A atuação do lingüista deixa de ser permanente e passa a ser eventual: quando necessário for. Ele deixa de ser o falante instrumentalizado da língua, com cujo povo ele identifica sua carreira - o criador da escrita, o formulador da gramática, o pai do dicionário -, e passa a ser um especialista nos fenômenos lingüístico-culturais decorrentes da introdução da escrita em comunidades antes ágrafas.

O pesquisador passa a ser o professor índio que, do seio de sua prática pedagógica, envolvido com as questões aí suscitadas, propõe procedimentos numa ordem que lhe parece adequada e que não precisa de maneira nenhuma seguir aquela preconizada pela disciplina universitária chamada lingüística: primeiro a descrição - fonética, fonologia, morfologia, sintaxe -, depois os estudos sociolingüísticos etc.

Com isso o assessor sofre uma mudança de função: não desaparece, mas sua experiência se dilui. Nem sempre é preciso aumentar, às vezes é imprescindível diminuir nossa ação em determinados lugares para que as coisas andem por si mesmas e para que se garanta que aquele é o projeto dos povos indígenas.

Retorno à citação do início do texto, à fala do professor Baniwa Gersen dos Santos Luciano, que definiu a assessoria adequada ao movimento indígena como uma assessoria qualificada e desinteressada. Qualificada por conseguir perceber a natureza do trabalho que realiza e, dentro dele, por conseguir, na prática, executar seu trabalho sem sacralizar o conhecimento técnico, homologado pela mais alta instituição do saber na nossa sociedade: a universidade; e desinteressada porque subordinada ao movimento indígena e pronta a aceitar, a qualquer instante, mudanças de rumo e de perspectivas. Aqui acredito tocar centralmente no assunto alteridade: respeitar a diferença dos povos indígenas é oferecer-lhes aquilo que precisam e querem quando precisam e querem.

Não há nessa argumentação nenhuma redução do valor do lingüista. Descrever línguas e formular teorias sobre como as línguas funcionam é uma nobre atividade e deve ser estimulada num país com tão poucos especialistas no assunto. Apenas não devemos cometer o equívoco de achar que essas atividades são o compromisso do lingüista com os povos indígenas, que o lingüista é, como diz Wetzels (1997, p. 2), "o mediador entre a cultura da classe dominante e aquela das minorias indígenas oprimidas". Esse não é seu papel.

Nesse sentido, é muito elucidativo verificar a contribuição dos lingüistas ditos "acadêmicos" aos povos indígenas mexicanos segundo a 
percepção de Dora Pellicer (1993, pp. 36-37), em uma seção do capítulo de "Oralidad y escritura de la literatura indígena: Una aproximación histórica", intitulado "Fue entonces cuando las lenguas indígenas pasaron de manos de los misioneros a las de los eruditos":

No obstante, la labor de los especialistas mexicanos en el mundo académico no tuvo efecto alguno en la legitimación del uso de estos idiomas en el contexto de la nación independiente. Pueden argumentarse varias razones de que ello ocurriera así. Pero una determinante principal es que aparentemente no hubo, por parte de este gremio, tan interesado en descripciones, comparaciones y estudios dialectales, el propósito de lograr, mediante sus conocimientos acumulados, la reivindicación del uso de estas lenguas. Para esa recién constituida intelectualidad mexicana - cuyos miembros, poseedores de una profusa erudición, se mantenían al día de la moderna filología - los idiomas nativos constituyeron un apasionante objeto de estudio, pero nada más. En el terreno ideológico todos ellos compartieron, sin someterlo a discusión profunda, el ideal nacional de una lengua común (..).

A experiência brasileira tem mostrado, com poucas exceções, ou puro interesse acadêmico pelas línguas indígenas, sem nenhuma espécie de comprometimento político para com os povos indígenas, num comportamento próximo ao que Pellicer aponta para os intelectuais mexicanos do século XIX, ou, ao contrário, assessorias lingüísticas que se fazem porta-vozes dos interesses indígenas e que acabam, por sua força e posição, abafando processos próprios de reflexão, substituindo uma racionalidade comunicativa por uma racionalidade técnica desenvolvida pelo Ocidente nos últimos 100 anos.

De fato acredito, como diz ainda Wetzels, que "as línguas não têm donos". Só que, para mim, dizer isso tem um sentido diverso do adotado no texto do autor: estou dizendo que os lingüistas não são donos da língua, que seu fazer metodológico não é uma garantia de que as coisas devem ocorrer naquela ordem e não noutra, naquela direção e não em outra, porque essas direções e a velocidade da marcha têm de ser deliberadas pelos agentes culturais indígenas envolvidos no processo, e para isso precisamos garantir espaços para a tomada de decisões. Precisamos, de certo modo, nos retirar de cena para propiciar o desenvolvimento de um espaço indígena de formulação de estratégias, essencial 
a qualquer projeto de autonomia. Nesse sentido, gostaria de citar um trecho de Michel de Certeau sobre a diferença entre tática e estratégia.

\begin{abstract}
Chamo de estratégia o cálculo (ou a manipulação) das relações de forças que se torna possível a partir do momento em que um sujeito de querer e poder (uma empresa, um exército, uma cidade, uma instituição científica) pode ser isolado. A estratégia postula um lugar suscetível de ser circunscrito como algo próprio e ser a base de onde se podem gerir as relações com uma exterioridade de alvos ou ameaças (...). Gesto cartesiano, quem sabe: circunscrever um próprio num mundo enfeitiçado pelos poderes invisíveis do outro. Gesto da modernidade científica, política ou militar. (...) chamo de tática a ação calculada que é determinada pela ausência de um próprio. Então nenhuma delimitação de fora lhe fornece a condição de autonomia. A tática não tem por lugar senão o do outro. E por isso deve jogar com o terreno que lhe é imposto tal como o organiza a lei de uma força estranha. Não tem meios para se manter em si mesma, à distância, numa posição recuada, de previsão e de convocação própria: a tática é movimento "dentro do campo de visão do inimigo", como dizia von Büllow, e no espaço por ele controlado. Ela não tem, portanto, a possibilidade de dar a si mesma um projeto global nem de totalizar o adversário num espaço distinto, visível e objetivável. Ela opera golpe por golpe, lance por lance. Aproveita as "ocasiões" e delas depende, sem bases para estocar benefícios, aumentar a propriedade e prever saídas. O que ela ganha não se conserva. (1996, p. 100)
\end{abstract}

Acredito que nossa retirada dos processos de tomada de decisão significa, antes de mais nada, a retirada da razão técnica interna às disciplinas universitárias que representamos, do lugar de centralidade que ela ocupa para nós e que, no mais das vezes, imputamos ao movimento indígena. Dar espaço para a alteridade significa dar espaço para que a razão comunicativa ligada à pragmática dos objetivos determinados coletivamente pelo povo indígena em questão, por intermédio de suas lideranças - sejam quais forem os processos de representatividade ou de representação tradicionais desses povos -, prevaleça sobre as lições de nossa própria experiência histórica, que não têm, como sabemos, valor prescritivo para outras comunidades humanas, com outro ethos que não o nosso.

Voltamos aqui à ação pedagógica: a assessoria está aprendendo com os povos indígenas a pensar a alteridade. Aos poucos, o confronto 
com a alteridade, com essa alteridade radical que são para nós - os chamados "ocidentais" - as racionalidades não-ocidentais, obrigar-nos-á a transformar nossa prática metodológica e profissional.

Quem fica imune, quem passa pela experiência de se confrontar com essa alteridade radical e sai incólume, é porque tem a sensibilidade embotada pelos preconceitos que nossa sociedade criou para justificar a subordinação dos outros povos: impossível não relativizar nosso conhecimento técnico, não passar a descrer da sacralização que fazemos de certos procedimentos ditos científicos, impossível deixar de historicizar a nossa experiência. Ao fazê-lo, ao historicizar nossa experiência, nos abrimos para a multiplicidade da experiência humana, expressa nas diferentes culturas com as quais trabalhamos e pelas quais nos engajamos.

Uma crítica metodológica e uma crítica epistemológica estão, portanto, a caminho. Sua autoria será compartilhada: o movimento indígena organizado, com suas demandas e com sua racionalidade, e as assessorias, a serviço desse movimento, com sua capacidade de pensar sobre novas bases, serão agenciadores de profundas repercussões no nosso fazer lingüístico, historiográfico, matemático - enfim, em todas as áreas e, sobretudo, quero crer, na área pedagógica.

\section{What linguistics wants and what one wants from linguistics}

ABSTRACT: The text points out the fact that the commitment of the linguist engaged with indigenous societies, can't be, on the contrary to the generalized belief, the elaboration of the descriptions of the indigenous languages, since the descriptions aren't essential to the process of creation of the written traditions to old languages considered unwritten.

Bibliografia

BAKHTIN, M. / VOLOSHINOV. Marxismo e filosofia da linguagem. São Paulo: Hucitec, 1978.

CAGLIARI, Luiz Carlos. Alfabetização e lingüística. São Paulo: Scipione, 1990.

CARDONA, G.R. Antropología de la escritura. Barcelona: Gedisa, 1994. 
DE CERTEAU, M. A invenção do cotidiano: Artes de fazer. Petrópolis: Vozes, 1996.

FAUNDEZ, A. A expansão da escrita na África e na América Latina. Rio de Janeiro: Paz e Terra, 1994.

FRAGO, A. Viñao. Alfabetização na sociedade e na história. Porto Alegre: Artes Médicas,1993.

GNERRE, M. Linguagem, escrita e poder. São Paulo: Martins Fontes, 1987.

HAMEL, R.E. "Políticas y planificación del lenguaje: Una introducción". Iztapalapa 29 - Revista de Ciencias Sociales y Humanidades, ano 13, janeiro-julho, 1993, pp. 5-39.

MONTEMAYOR, C. (org.). Situación actual y perspectivas de las literaturas en lenguas indígenas. México: Consejo Nacional para la Cultura y las Artes, 1993 (Série Pensar la Cultura).

OLIVEIRA, G.M. de e OLIVEIRA, S.M. "Formação de professores: Um caso de política lingüística nas comunidades kaingang". I Encontro de Variação Lingüística do Cone Sul. Porto Alegre, 2 a 4/9/1996 (cf. Anais do encontro).

PELLICER, D. "Oralidad y escritura de la literatura indígena: Una aproximación histórica”. In: MONTEMAYOR, C. (org.). Situación actual y perspectivas de las literaturas en lenguas indígenas. México: Consejo Nacional para la Cultura y las Artes, 1993 (Série Pensar la Cultura).

SCHARLAU, B. e MÜNZEL, M. Mündliche Kultur und Schriftradition bei Indianern Lateinamerikas. Frankfurt: Campus Verlag, 1986.

SILVA, M.F. da. "A conquista da escola: Educação escolar indígena e movimento de professores indígenas no Brasil". Em Aberto 63 (Educação escolar indígena), 1994, pp. 38-53.

WETZELS, Leo. "As línguas não têm donos". III Encontro Nacional de Acervos Literários Brasileiros: Ética e política de gestão de acervos literários. Porto Alegre: CPGL-PUCRS, de 20 a 22/5/1997 (cf. Anais do encontro). 